\title{
Diet and pregnancy status in Australian women
}

\author{
Alexis Hure ${ }^{1,2, *}$, Anne Young ${ }^{3}$, Roger Smith ${ }^{2}$ and Clare Collins ${ }^{1}$ \\ ${ }^{1}$ Nutrition and Dietetics, School of Health Sciences, University of Newcastle, Callaghan, New South Wales \\ 2308, Australia: ${ }^{2}$ Mothers and Babies Research Centre, Hunter Medical Research Institute, John Hunter Hospital, \\ Newcastle, New South Wales, Australia: ${ }^{3}$ Research Centre for Gender, Health and Ageing, University of \\ Newcastle, Callaghan, New South Wales, Australia
}

Submitted 29 January 2008: Accepted 9 June 2008: First published online 23 July 2008

\begin{abstract}
Objective: To investigate and report the diet quality of young Australian women by pregnancy status.

Design: Pregnancy status was defined as pregnant ( $n$ 606), trying to conceive ( $n$ 454), had a baby in the last 12 months ( $n$ 829) and other ( $n 5597)$. The Dietary Questionnaire for Epidemiological Studies was used to calculate diet quality using the Australian Recommended Food Score (ARFS) methodology. Nutrient intakes were compared with the Nutrient Reference Values for Australia and New Zealand. Setting: A population-based cohort participating in the Australian Longitudinal Study on Women's Health (ALSWH).

Subjects: A nationally representative sample of Australian women, aged 25 to 30 years, who completed Survey 3 of the ALSWH. The 7486 women with biologically plausible energy intake estimates, defined as $>4.5$ but $<20 \cdot 0 \mathrm{MJ} / \mathrm{d}$, were included in the analyses.

Results: Pregnancy status was not significantly predictive of diet quality, before or after adjusting for area of residence and socio-economic status. Pregnant women and those who had given birth in the previous 12 months had marginally higher

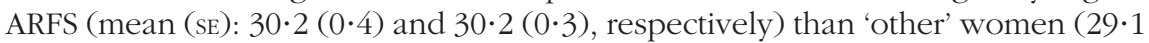
$(0 \cdot 1))$. No single food group accounted for this small difference. Across all pregnancy categories there were important nutrients that did not meet the current nationally recommended levels of intake, including dietary folate and fibre.

Conclusion: Women do not appear to consume a wider variety of nutritious foods when planning to become pregnant or during pregnancy. Many young Australian women are failing to meet key nutrient targets as nationally recommended.
\end{abstract}

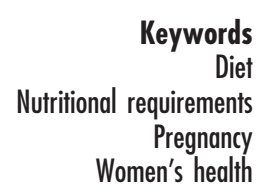

Maternal nutrition during pregnancy and in the periconception period is a key modifier of health outcomes for both mother and child, not only in the prenatal period but also much longer-term ${ }^{(1-3)}$. There is now considerable evidence that variations in fetal nourishment can elicit permanent adjustments in a wide range of systems, including endocrine, organ and metabolic, and that this intra-uterine 'programming' may persist after birth ${ }^{(4)}$. It is therefore of interest to know at a population level about the dietary practices and nutritional adequacy of intakes in women of childbearing age. Additionally, there is a need to understand whether these are altered in the lead up to, and over the course of, pregnancy and whether changes persist postnatally.

There are very few large studies in Western populations that have looked at the dietary quality of pregnant women, whether in isolation or in reference to a nonpregnant control group. The Avon Longitudinal Study of Pregnancy and Childhood (ALSPAC) is among the largest worldwide and has dietary data recorded for 11923 women in the south-west of England at 32 weeks' gestation. The ALSPAC research team have assessed the adequacy of the diets of their pregnant participants and found that while most nutrient intakes met the national recommendations, there were others of importance, including folate, $\mathrm{Fe}, \mathrm{Mg}$ and $\mathrm{K}$, that did not ${ }^{(5)}$. However that study did not include a control, non-pregnant cohort. Similar findings have been reported in a number of smaller studies in both the $\mathrm{UK}^{(6)}$ and the $\mathrm{USA}^{(7)}$. The Norwegian Mother and Child Cohort Study (MoBa) is currently underway with some dietary data published for 40108 participants $^{(8)}$.

In Australia limited information is available about what pregnant women are consuming and their patterns of intake. There are a number of studies during pregnancy that include some form of dietary assessment ${ }^{(9-11)}$, yet there are no nationally representative data reporting on total diet. The 1995 Australian National Nutrition Survey, 
which is the most current data set, included food and nutrient intake data obtained using the $24 \mathrm{~h}$ recall method and a complementary FFQ, completed by both pregnant and non-pregnant participants ${ }^{(12)}$. However, only 162 pregnant women $(1 \cdot 2 \%$ of all responders) were included in that survey and analysis. Like most other dietary studies in pregnancy, it has focused primarily on nutrient consumption $^{(13)}$. While useful, nutrient consumption data do not take into account dietary patterns or the actual foods and food groups from which they were derived.

Various studies have combined multiple dietary components into a single diet quality exposure or score, trading detailed nutrient information for a summary value $^{(14-17)}$. Those that do so in accordance with evidence-based national dietary guidelines have been able to demonstrate correlations with indicators of morbidity and mortality ${ }^{(18)}$. This holds true for the very few studies assessing diet quality in pregnancy ${ }^{(17,19)}$. Favourable outcomes, including reduced risk of neural tube defects ${ }^{(17)}$ and increased birth weight ${ }^{(19)}$, have been associated with better diet quality. It is within this context that we have used extensive dietary data on a large cohort of Australian women to determine the association between pregnancy status and diet quality.

\section{Subjects and methods}

\section{Data collection}

The present study used cross-sectional, self-reported data collected prospectively as part of the Australian Longitudinal Study on Women's Health (ALSWH). The ALSWH recruited 40000 'young', 'mid-aged' and 'older' women with the issue of the baseline surveys in 1996. The research was designed to explore factors that relate to health promotion or diminution in women who are broadly representative of the Australian population. Ethical approval for the study was obtained from the Human Research Ethics Committee of the University of Newcastle. Further details of the ALSWH have been published elsewhere ${ }^{(20-22)}$.

These analyses of diet quality in pregnancy and other states include data from the young cohort, who were aged 25 to 30 years at the time of completing Survey 3 in March 2003. The dietary data for the young cohort have not been published previously and this is, at present, the largest study in Australia to have investigated diet quality in women of childbearing age.

The Dietary Questionnaire for Epidemiological Studies (DQES) version 2, a 200-item FFQ, was included in the present survey. This FFQ has previously been validated in a cohort of young Australian women ${ }^{(23)}$. Collins et al. have reported a method for summarising diet quality using the DQES and have measured the association between their Australian Recommended Food Score (ARFS) and indices of morbidity, including health service utilisation and self-perceived health ${ }^{(24,25)}$. The ALSWH survey also included a range of measures of demographic characteristics, health behaviours and psychosocial measures including area of residence, country of birth, marital status, height, weight, smoking, frequency and intensity of physical activity, highest educational qualification, ability to manage on income, self-reported health and doctor-diagnosed medical conditions.

\section{Sample}

Of the total ALSWH cohort, 14247 women aged 18 to 23 years participated in the baseline survey (Survey 1) of young women in 1996. This was estimated to be a $41-42 \%$ response rate for this aged cohort ${ }^{(21)}$. From the initial young cohort, 9076 women aged 25 to 30 years in 2003 completed Survey 3, with attrition being mainly due to young women having changed address and not being located $^{(26)}$. Four groups were used to define pregnancy status: (i) pregnant ( $n$ 606); (ii) trying to conceive ( $n 454)$; (iii) had a baby in the last 12 months ( $n$ 829); and (iv) other ( $n$ 5597). Subjects were excluded from these analyses if: (i) their pregnancy status could not be determined from their survey responses ( $n$ 111); (ii) they could be grouped into more than one pregnancy category ( $n 61$ ); or (iii) their calculated energy intake was $<4.5$ or $>20 \cdot 0 \mathrm{MJ} / \mathrm{d}$ ( $n$ 1418). Energy values outside this range were considered biologically improbable and indicative of misreporting. A total of 7486 women were included in the present analysis.

\section{Australian Recommended Food Score}

The development of the ARFS has been described in detail elsewhere ${ }^{(24,25)}$. Briefly, it was modelled on the Recommended Food Score developed by Kant and Thompson in the USA ${ }^{(27)}$. The ARFS is calculated based on regular consumption of items listed in the DQES FFQ that are consistent with national recommendations, including the Dietary Guidelines for Australian Adults ${ }^{(28)}$ and the core foods as outlined in the Australian Guide to Healthy Eating ${ }^{(29)}$. Scoring is mostly independent of the reported quantities of foods consumed and frequencies have been dichotomised, reducing the measurement error typically associated with FFQ. Foods that are not considered to make a beneficial contribution to dietary intake have not been scored, with the exception of ice cream and cheese.

One point was allocated for each food or beverage item contained within the DQES that met the above criteria and was usually consumed once weekly or more in the previous year. An additional point was available for specific types and amounts of core foods consumed including: at least two fruit servings daily; at least four vegetable servings daily; using high-fibre, wholemeal, rye or multigrain breads; having at least four slices of bread daily; using polyunsaturated or monounsaturated spreads or no fat spread; having one or two eggs weekly; using 
reduced-fat or skimmed milk; using soya milk; consuming at least $500 \mathrm{ml}$ milk daily; using ricotta or cottage cheese; using low-fat cheese; consuming ice cream and cheese each less than once weekly; and consuming yoghurt more than once weekly. The 2 points that were available in the original ARFS for questions related to alcohol frequency and quantity of intake were removed from these analyses as the guidelines for safe alcohol consumption during pregnancy differ from those for the non-pregnant population ${ }^{(30)}$. Consequently the maximum ARFS that could be achieved was 72 .

\section{Nutrient reference values}

The National Health and Medical Research Council of Australia has recently produced a set of nutrient reference values (NRV) which describe the amount of specific nutrients required on average, on a daily basis, for sustenance or avoidance of nutritional deficiency ${ }^{(31)}$. An estimated average requirement (EAR) is defined as 'a daily nutrient level estimated to meet the requirements of half the healthy individuals in a particular life stage and gender group, ${ }^{,(31)}$. It is used to estimate the prevalence of inadequate intakes within a group. Recommended dietary intakes (RDI) are commonly cited and are calculated from the EAR. However RDI are more appropriate when assessing an individual's dietary intake, rather than group means as in our study, as they are the levels defined to meet the known nutritional needs of practically all $(97 \cdot 5 \%)$ healthy people ${ }^{(29)}$. Hence EAR have been presented whenever available. When they are not, adequate intakes (AI) have been used instead. AI are the average daily nutrient intake level based on observed or experimentally-determined approximations or estimates of nutrient intake by a group (or groups) of apparently healthy people that are assumed to be adequate ${ }^{,(31)}$.

\section{Statistical analyses}

To improve the validity of the dietary analyses, women with daily energy intakes $<4.5$ or $>20.0 \mathrm{MJ} / \mathrm{d}$ were excluded. Often, BMR is calculated for each individual and the ratio of reported energy intake to BMR is used to help reduce erroneous data ${ }^{(32)}$. However the weights were not recorded for pregnant participants in the present study, and therefore BMR could not be calculated. Meltzer et al. have presented an alternative for handling uncertainties in reported dietary intake estimates for pregnant women, suggesting these energy values as appropriate cut-offs ${ }^{(8)}$. The same cut-offs have been applied across all pregnancy groups.

The characteristics of women in each of the pregnancy groups were compared and standard deviations were calculated for means. The relationship between pregnancy status and ARFS was assessed using a general linear model, with area of residence and educational attainment included as covariates, to adjust for the sampling frame and for socio-economic status. Given the large sample size and the number of comparisons that were performed, $P$ values $<0 \cdot 001$ were considered statistically significant, unless otherwise specified. Tests of association were performed using $\chi^{2}$ analyses. Comparisons of the food component scores that make up the ARFS were made between pregnancy groups. Mean energy and nutrient intakes by ARFS quintile (energy-standardised per $1000 \mathrm{kcal})$ were calculated to ensure that the ARFS was indeed a measure of nutritional adequacy or diet quality in this cohort. All data manipulation and statistical analyses were performed using the Statistical Analysis Systems statistical software package version 8 (SAS Institute, Cary, NC, USA).

\section{Results}

The women participating in the young cohort had a mean age of $27 \cdot 2$ (SD 1.5) years. At Survey 3, 8.1\% of women reported that they were currently pregnant, $6 \cdot 1 \%$ reported that they were trying to conceive and $11 \cdot 1 \%$ reported having given birth in the previous 12 months. All women who were not in one of the above categories were classed as 'other' $(74 \cdot 8 \%)$. The participant demographics according to each pregnancy group are reported in Table 1.

Women who reported being pregnant, trying to conceive or having given birth in the previous 12 months were more likely to be married or in a de facto relationship, and to live in a rural location, compared with 'other' women. Women in the 'other' category were more likely to have been born outside Australia, to have post-school education and to do more physical activity. A significantly lower proportion of women who were either pregnant or had given birth in the previous 12 months reported being a current smoker. Interestingly, women who were trying to conceive had a higher proportion of poor self-reported health compared with all other categories. Those who had given birth in the previous 12 months were most likely to report having difficulty managing on their available income $(54 \cdot 4 \%$ v. 38.4\% for 'other' women).

Pregnancy status was not significantly predictive of the ARFS, even after adjusting for area of residence and education (Table 2). Women who were pregnant or had given birth in the previous 12 months had slightly higher ARFS than the women classed as 'other' $(P=0 \cdot 006)$, although this was a mean difference of only $1 \cdot 1$ points.

Examination of the component scores that make up the ARFS between pregnancy groups revealed very small absolute differences (Table 3). The vegetables component was overall the most highly scored group relative to the total number of points available in each component. Within the protein foods component (includes nut/bean/ soya/egg, meat and fish) and overall, the nut/bean/soya/ egg grouping was the most poorly scored, with on average less than 2 points obtained out of the available 
Table 1 Participant demographics for the young cohort of the Australian Longitudinal Study on Women's Health according to pregnancy status

\begin{tabular}{|c|c|c|c|c|c|c|c|c|}
\hline & \multicolumn{2}{|c|}{$\begin{array}{c}\text { Pregnant } \\
(n 606,8 \cdot 1 \%)\end{array}$} & \multicolumn{2}{|c|}{$\begin{array}{c}\text { Trying } \\
\text { (n 454, 6.1\%) }\end{array}$} & \multicolumn{2}{|c|}{$\begin{array}{l}\text { Birth }<12 \text { months ago } \\
\quad(n 829,11 \cdot 1 \%)\end{array}$} & \multicolumn{2}{|c|}{$\begin{array}{c}\text { Other } \\
\text { (n 5597, } 74 \cdot 8 \% \text { ) }\end{array}$} \\
\hline & $n$ & $\%$ & $n$ & $\%$ & $n$ & $\%$ & $n$ & $\%$ \\
\hline \multirow[t]{2}{*}{ Excluded based on energy $<4.5$ or $>20.0 \mathrm{MJ} / \mathrm{d}$} & 47 & $7 \cdot 2^{*}$ & 81 & $15 \cdot 1$ & 58 & $6 \cdot 5^{*}$ & 1212 & $17 \cdot 8$ \\
\hline & Mean & $\mathrm{SD}$ & Mean & SD & Mean & SD & Mean & SD \\
\hline Age (years) & $27 \cdot 4^{*}$ & $1 \cdot 4$ & $27 \cdot 5^{\star}$ & $1 \cdot 4$ & $27 \cdot 5^{\star}$ & $1 \cdot 3$ & $27 \cdot 1$ & $1 \cdot 5$ \\
\hline Height (cm) & $165 \cdot 7$ & $7 \cdot 0$ & $166 \cdot 7$ & $6 \cdot 9$ & $166 \cdot 3$ & $6 \cdot 9$ & $166 \cdot 2$ & $7 \cdot 2$ \\
\hline \multirow[t]{2}{*}{ Weight (kg) } & + & & $70 \cdot 4$ & $16 \cdot 4$ & $69 \cdot 4^{*}$ & $14 \cdot 0$ & $67 \cdot 1$ & $14 \cdot 9$ \\
\hline & \multicolumn{2}{|c|}{$\%$} & \multicolumn{2}{|c|}{$\%$} & \multicolumn{2}{|c|}{$\%$} & \multicolumn{2}{|c|}{$\%$} \\
\hline Born in Australia & \multicolumn{2}{|c|}{$94 \cdot 8^{*}$} & \multicolumn{2}{|c|}{$94 \cdot 3^{\star}$} & \multicolumn{2}{|c|}{$94 \cdot 2^{*}$} & \multicolumn{2}{|c|}{$91 \cdot 0$} \\
\hline Post-school qualifications & \multicolumn{2}{|c|}{$70 \cdot 1^{*}$} & \multicolumn{2}{|c|}{$68 \cdot 2^{*}$} & \multicolumn{2}{|c|}{$65 \cdot 6^{*}$} & \multicolumn{2}{|c|}{$75 \cdot 4$} \\
\hline Urban resident & \multicolumn{2}{|c|}{$65 \cdot 1^{*}$} & \multicolumn{2}{|c|}{$67 \cdot 7^{\star}$} & \multicolumn{2}{|c|}{$60 \cdot 0^{*}$} & \multicolumn{2}{|c|}{$75 \cdot 0$} \\
\hline Married/de facto relationship & \multicolumn{2}{|c|}{$96 \cdot 2^{*}$} & \multicolumn{2}{|c|}{$96 \cdot 7^{*}$} & \multicolumn{2}{|c|}{$93 \cdot 9^{*}$} & \multicolumn{2}{|c|}{$51 \cdot 4$} \\
\hline Current smoker & \multicolumn{2}{|c|}{$9 \cdot 2^{*}$} & \multicolumn{2}{|c|}{$22 \cdot 7$} & \multicolumn{2}{|c|}{$17 \cdot 1^{*}$} & \multicolumn{2}{|c|}{$25 \cdot 9$} \\
\hline Depressive symptoms (CESD-10 score $\geq 10) \ddagger$ & \multicolumn{2}{|c|}{$20 \cdot 3^{*}$} & \multicolumn{2}{|c|}{$22 \cdot 4^{*}$} & \multicolumn{2}{|c|}{$25 \cdot 0$} & \multicolumn{2}{|c|}{$26 \cdot 1$} \\
\hline Inactive/low level physical activity & \multicolumn{2}{|c|}{$68 \cdot 9^{*}$} & \multicolumn{2}{|c|}{$45 \cdot 6^{\star}$} & & & & \\
\hline Poor/fair self-reported health & & & 12 & & & & & \\
\hline Difficulty managing on available income & 39 & & 38 & & & & & \\
\hline
\end{tabular}

*Statistically significant difference $(P<0.05)$ compared with the 'other' group.

tData on weight during pregnancy were not available.

$\ddagger$ Center for Epidemiologic Studies Depression Scale ${ }^{(33)}$.

Table 2 Unadjusted and adjustedt mean Australian Recommended Food Scores (ARFS) for the young cohort of the Australian Longitudinal Study on Women's Health according to pregnancy status

\begin{tabular}{|c|c|c|c|c|c|c|}
\hline Pregnancy status & Unadjusted mean ARFS & SE & $P$ value & Adjustedt mean ARFS & SE & $P$ value \\
\hline Pregnant ( $n 606,8 \cdot 1 \%)$ & $30 \cdot 2$ & $0 \cdot 4$ & 0.007 & $30 \cdot 2$ & $0 \cdot 4$ & 0.006 \\
\hline Trying (n 454, 6.1\%) & $29 \cdot 4$ & $0 \cdot 4$ & 0.597 & $29 \cdot 5$ & $0 \cdot 4$ & $0 \cdot 346$ \\
\hline Birth $<12$ months ago ( $n 829,11 \cdot 1 \%)$ & $30 \cdot 0$ & 0.3 & 0.023 & $30 \cdot 2$ & 0.3 & 0.002 \\
\hline Other ( $n 5597,74.8 \%)$ & $29 \cdot 2$ & $0 \cdot 1$ & $\ddagger$ & $29 \cdot 1$ & $0 \cdot 1$ & $\ddagger$ \\
\hline
\end{tabular}

tAdjusted for level of education and area of residence.

‡Reference to which all groups have been compared.

Table 3 Mean and standard deviation component scores and total Australian Recommended Food Score (ARFS) for the young cohort of the Australian Longitudinal Study on Women's Health according to pregnancy status

\begin{tabular}{|c|c|c|c|c|c|c|c|c|}
\hline \multirow[b]{2}{*}{ Component score (maximum) } & \multicolumn{2}{|c|}{$\begin{array}{c}\text { Pregnant } \\
(n 606,8 \cdot 1 \%)\end{array}$} & \multicolumn{2}{|c|}{$\begin{array}{c}\text { Trying } \\
\text { (n 454, 6.1\%) }\end{array}$} & \multicolumn{2}{|c|}{$\begin{array}{c}\text { Birth }<12 \text { months ago } \\
(n 829,11 \cdot 1 \%)\end{array}$} & \multicolumn{2}{|c|}{$\begin{array}{c}\text { Other } \\
\text { (n 5597, } 74 \cdot 8 \% \text { ) }\end{array}$} \\
\hline & Mean & SD & Mean & SD & Mean & SD & Mean & SD \\
\hline Vegetables (22) & $11 \cdot 7$ & $4 \cdot 3$ & $11 \cdot 8$ & $4 \cdot 4$ & $12 \cdot 4$ & $4 \cdot 2$ & $11 \cdot 8$ & $4 \cdot 7$ \\
\hline Fruit (14) & $6 \cdot 0^{*}$ & $3 \cdot 2$ & $5 \cdot 1$ & $3 \cdot 2$ & $5 \cdot 4$ & $3 \cdot 2$ & $5 \cdot 1$ & $3 \cdot 3$ \\
\hline Grain (14) & $4 \cdot 8^{*}$ & $1 \cdot 8$ & $4 \cdot 4$ & $1 \cdot 8$ & $4 \cdot 8^{*}$ & $1 \cdot 8$ & $4 \cdot 4$ & $1 \cdot 8$ \\
\hline Dairy (7) & $2 \cdot 6$ & $1 \cdot 2$ & $2 \cdot 7$ & $1 \cdot 2$ & $2 \cdot 6$ & $1 \cdot 2$ & $2 \cdot 8$ & $1 \cdot 2$ \\
\hline Nut/beans/soyat (7) & $1 \cdot 7$ & $1 \cdot \overline{1}$ & $1 \cdot 6$ & $1 \cdot 0$ & $1 \cdot 7$ & $1 \cdot 0$ & $1 \cdot 9$ & $1 \cdot 3$ \\
\hline Meatt (5) & $2 \cdot 4^{*}$ & $1 \cdot 2$ & $2 \cdot 5^{\star}$ & $1 \cdot 2$ & $2 \cdot 5^{*}$ & $1 \cdot 2$ & $2 \cdot 2$ & $1 \cdot 3$ \\
\hline Fisht (2) & $0 \cdot 7$ & $0 \cdot 7$ & 0.7 & $0 \cdot 8$ & $0 \cdot 7$ & 0.7 & $0 \cdot 7$ & $0 \cdot 8$ \\
\hline Fat (1) & 0.4 & 0.5 & 0.5 & 0.5 & 0.4 & 0.5 & 0.5 & 0.5 \\
\hline Total ARFS (72) & $30 \cdot 2$ & $8 \cdot 4$ & $29 \cdot 4$ & $8 \cdot 6$ & $30 \cdot 5$ & $8 \cdot 4$ & $29 \cdot 4$ & $9 \cdot 0$ \\
\hline
\end{tabular}

*Statistically significant $(P<0001)$ differences between groups.

tSubcomponents of the protein foods category.

7 points for all groups. Fish and grain component scores were also low relative to the other food groups.

Pregnant women performed better on their intake of fruit, grain and meat compared with 'other' women. Similarly, women who had given birth in the previous 12 months gained more points from the grain and meat components. In all instances of statistical significance, there was less than one mean point of difference between pregnancy groups.

Table 4 reports mean intakes of selected macro- and micronutrients by quintile of ARFS, energy-standardised per $1000 \mathrm{kcal}$. Quintile 1 reflects the lowest ARFS and 


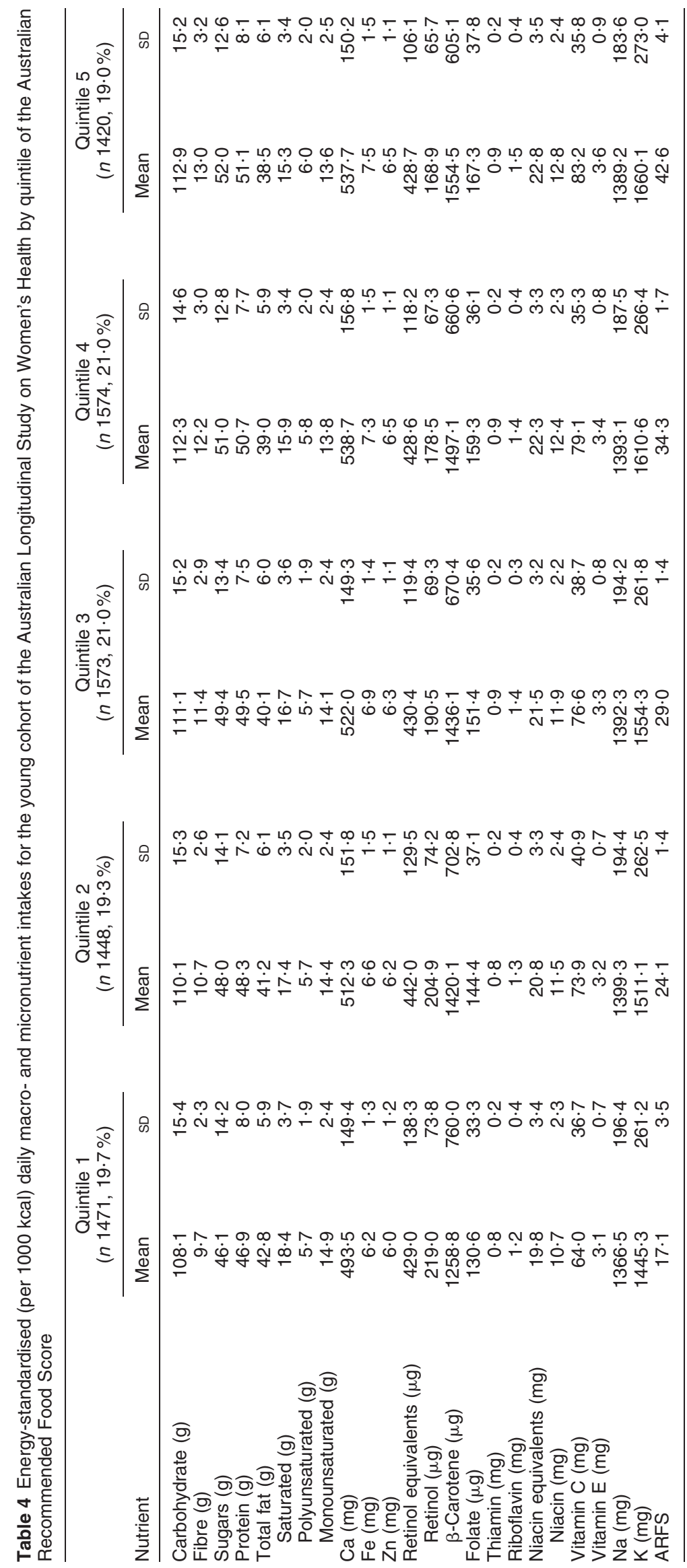


quintile 5 the highest. Carbohydrate, fibre, sugars, protein, polyunsaturated fat, $\mathrm{Ca}, \mathrm{Fe}, \mathrm{Zn}, \beta$-carotene, folate, thiamin, riboflavin, niacin, vitamin $\mathrm{C}$, vitamin $\mathrm{E}$ and $\mathrm{K}$ all increased as ARFS quintile increased. Conversely, total fat, saturated fat, monounsaturated fat and retinol decreased with increasing AFRS quintile. While the trend was less consistent for $\mathrm{Na}$, intake was highest in ARFS quintile 2.

All mean group intakes (Table 5) were above the estimated EAR or AI as outlined in Table 6 for protein, Ca, $\mathrm{Zn}$, retinol equivalents, thiamin, riboflavin, niacin and vitamin C. Nutrients that were consistently below the EAR or AI included dietary fibre, folate and vitamin E. In order to meet the EAR, Fe would need to have been markedly higher in the pregnant group. Mean Na intakes were higher than the recommended upper level of $2300 \mathrm{mg} / \mathrm{d}$ across all groups $^{(31)}$. Intake of $\mathrm{K}$ was lower than the recommended AI for women trying to conceive and 'others'. As lactation status could not be confirmed, all groups have been compared with either the pregnant or non-pregnant references; however, the NRV for women aged 19-30 years who are lactating have been provided to show the differences in nutritional requirements for this group.

Table 5 Daily macro- and micronutrient intakes for the young cohort of the Australian Longitudinal Study on Women's Health according to pregnancy status

\begin{tabular}{|c|c|c|c|c|c|c|c|c|}
\hline \multirow[b]{2}{*}{ Nutrient } & \multicolumn{2}{|c|}{$\begin{array}{c}\text { Pregnant } \\
(n 606,8 \cdot 1 \%)\end{array}$} & \multicolumn{2}{|c|}{$\begin{array}{c}\text { Trying } \\
\text { (n } 454,6 \cdot 1 \%)\end{array}$} & \multicolumn{2}{|c|}{$\begin{array}{c}\text { Birth }<12 \text { months ago } \\
\quad(n 829,11 \cdot 1 \%)\end{array}$} & \multicolumn{2}{|c|}{$\begin{array}{c}\text { Other } \\
\text { ( } n 5597,74 \cdot 8 \%)\end{array}$} \\
\hline & Mean & SD & Mean & SD & Mean & SD & Mean & SD \\
\hline Energy (kJ) & $7795 \cdot 1$ & $2326 \cdot 6$ & $7400 \cdot 5$ & $2282 \cdot 0$ & $8228 \cdot 0$ & $2396 \cdot 0$ & $7310 \cdot 6$ & $2272 \cdot 1$ \\
\hline Carbohydrate $(\mathrm{g})$ & $208 \cdot 5$ & $62 \cdot 1$ & $193 \cdot 2$ & $60 \cdot 4$ & $214 \cdot 8$ & $64 \cdot 4$ & $192 \cdot 7$ & $62 \cdot 1$ \\
\hline Fibre (g) & $20 \cdot 7$ & $7 \cdot 1$ & $19 \cdot 6$ & $6 \cdot 5$ & $21 \cdot 4$ & $7 \cdot 2$ & $19 \cdot 8$ & $7 \cdot 2$ \\
\hline Sugars $(\mathrm{g})$ & 95.9 & $33 \cdot 7$ & $84 \cdot 4$ & $30 \cdot 0$ & $94 \cdot 0$ & $31 \cdot 8$ & $84 \cdot 6$ & $31 \cdot 4$ \\
\hline Protein $(\mathrm{g})$ & $89 \cdot 0$ & $29 \cdot 8$ & $88 \cdot 8$ & $30 \cdot 1$ & $95 \cdot 2$ & $30 \cdot 0$ & $86 \cdot 2$ & $30 \cdot 1$ \\
\hline Total fat $(\mathrm{g})$ & $75 \cdot 6$ & $26 \cdot 6$ & 71.9 & $27 \cdot 7$ & $81 \cdot 6$ & $27 \cdot 7$ & $70 \cdot 9$ & $27 \cdot 0$ \\
\hline Saturated $(\mathrm{g})$ & $32 \cdot 3$ & $13 \cdot 0$ & $30 \cdot 3$ & $13 \cdot 0$ & $34 \cdot 5$ & $12 \cdot 9$ & $29 \cdot 3$ & $12 \cdot 4$ \\
\hline Polyunsaturated (g) & $10 \cdot 6$ & $4 \cdot 3$ & $9 \cdot 9$ & $4 \cdot 3$ & $11 \cdot 4$ & $4 \cdot 8$ & $10 \cdot 1$ & $4 \cdot 7$ \\
\hline Monounsaturated (g) & $26 \cdot 1$ & $9 \cdot 5$ & $25 \cdot 2$ & $10 \cdot 0$ & $28 \cdot 6$ & $10 \cdot 1$ & $25 \cdot 0$ & $10 \cdot 0$ \\
\hline $\mathrm{Ca}(\mathrm{mg})$ & $1007 \cdot 0$ & $316 \cdot 5$ & $912 \cdot 8$ & $277 \cdot 3$ & $971 \cdot 6$ & $289 \cdot 5$ & $875 \cdot 6$ & $285 \cdot 9$ \\
\hline $\mathrm{Fe}(\mathrm{mg})$ & $12 \cdot 8$ & $5 \cdot 1$ & $12 \cdot 3$ & $4 \cdot 6$ & $13 \cdot 8$ & $5 \cdot 0$ & $12 \cdot 0$ & $4 \cdot 6$ \\
\hline $\mathrm{Zn}(\mathrm{mg})$ & $11 \cdot 5$ & $4 \cdot 2$ & $11 \cdot 4$ & $4 \cdot 1$ & $12 \cdot 5$ & $4 \cdot 3$ & $11 \cdot 0$ & $4 \cdot 1$ \\
\hline Retinol equivalents $(\mu \mathrm{g})$ & $840 \cdot 5$ & $294 \cdot 1$ & $779 \cdot 9$ & $283 \cdot 6$ & $864 \cdot 7$ & $290 \cdot 9$ & $733 \cdot 6$ & 278.9 \\
\hline Retinol $(\mu \mathrm{g})$ & $411 \cdot 4$ & $163 \cdot 7$ & 338.5 & $156 \cdot 5$ & $404 \cdot 9$ & $158 \cdot 2$ & $325 \cdot 0$ & $156 \cdot 7$ \\
\hline$\beta$-Carotene $(\mu \mathrm{g})$ & $2570 \cdot 8$ & $1286 \cdot 3$ & $2644 \cdot 2$ & $1324 \cdot 0$ & $2754 \cdot 5$ & $1290 \cdot 9$ & $2446 \cdot 7$ & $1294 \cdot 3$ \\
\hline Folate $(\mu \mathrm{g})$ & $284 \cdot 4$ & $106 \cdot 2$ & 265.9 & $92 \cdot 0$ & 288.9 & $97 \cdot 4$ & $259 \cdot 7$ & $94 \cdot 4$ \\
\hline Thiamin (mg) & $1 \cdot 7$ & 0.7 & $1 \cdot 6$ & $0 \cdot 6$ & $1 \cdot 7$ & 0.6 & 1.5 & $0 \cdot 6$ \\
\hline Riboflavin (mg) & $2 \cdot 7$ & $1 \cdot 0$ & $2 \cdot 4$ & $0 \cdot 9$ & $2 \cdot 6$ & 0.9 & $2 \cdot 3$ & 0.9 \\
\hline Niacin equivalents (mg) & $39 \cdot 4$ & $14 \cdot 4$ & $38 \cdot 6$ & $13 \cdot 6$ & $42 \cdot 0$ & $13 \cdot 8$ & $37 \cdot 6$ & $13 \cdot 6$ \\
\hline Niacin (mg) & $22 \cdot 2$ & $9 \cdot 0$ & $21 \cdot 4$ & $8 \cdot 2$ & $23 \cdot 4$ & $8 \cdot 5$ & $20 \cdot 9$ & $8 \cdot 3$ \\
\hline Vitamin C (mg) & $152 \cdot 1$ & $86 \cdot 3$ & $135 \cdot 5$ & $81 \cdot \overline{9}$ & $140 \cdot 1$ & $78 \cdot 5$ & $129 \cdot 0$ & $74 \cdot 5$ \\
\hline Vitamin E (mg) & $6 \cdot 0$ & $2 \cdot 1$ & $5 \cdot 6$ & 1.9 & $6 \cdot 4$ & $2 \cdot 2$ & $5 \cdot 8$ & $2 \cdot 2$ \\
\hline $\mathrm{Na}(\mathrm{mg})$ & $2521 \cdot 6$ & $819 \cdot 9$ & $2474 \cdot 3$ & $885 \cdot 3$ & $2732 \cdot 4$ & $866 \cdot 3$ & $2430 \cdot 3$ & $834 \cdot 6$ \\
\hline $\mathrm{K}(\mathrm{mg})$ & $2950 \cdot 6$ & $888 \cdot 4$ & $2752 \cdot 4$ & $789 \cdot 8$ & $2946 \cdot 6$ & $823 \cdot 5$ & $2674 \cdot 0$ & $796 \cdot 6$ \\
\hline
\end{tabular}

Table 6 Daily nutrient reference values for Australia and New Zealand ${ }^{(31)}$ : selected macro- and micronutrients

\begin{tabular}{|c|c|c|c|c|c|c|}
\hline \multirow[b]{2}{*}{ Nutrient } & \multicolumn{2}{|c|}{ Women $19-30$ years } & \multicolumn{2}{|c|}{ Pregnancy $19-30$ years } & \multicolumn{2}{|c|}{ Lactation $19-30$ years } \\
\hline & EAR & $\mathrm{Al}$ & EAR & $\mathrm{Al}$ & EAR & $\mathrm{Al}$ \\
\hline Protein $(\mathrm{g})$ & 37 & & $49 \ddagger$ & & 54 & \\
\hline Fibre $(\mathrm{g})$ & & 25 & & 28 & & 30 \\
\hline $\mathrm{Ca}(\mathrm{mg})$ & 840 & & 840 & & 840 & \\
\hline $\mathrm{Fe}(\mathrm{mg})$ & $8 \cdot 0$ & & 22 & & $6 \cdot 5$ & \\
\hline $\mathrm{Zn}(\mathrm{mg})$ & $6 \cdot 5$ & & $9 \cdot 0$ & & $10 \cdot 0$ & \\
\hline Retinol equivalents $(\mu \mathrm{g})$ & 500 & & 550 & & 800 & \\
\hline Folate $(\mu \mathrm{g}) \dagger$ & 320 & & 520 & & 450 & \\
\hline Thiamin (mg) & 0.9 & & $1 \cdot 2$ & & $1 \cdot 2$ & \\
\hline Riboflavin (mg) & 0.9 & & $1 \cdot 2$ & & $1 \cdot 3$ & \\
\hline $\operatorname{Niacin}(\mathrm{mg})$ & 11 & & 14 & & 13 & \\
\hline Vitamin C (mg) & 30 & & 40 & & 60 & \\
\hline Vitamin E (mg) & 7 & & 7 & & 11 & \\
\hline $\mathrm{Na}(\mathrm{mg})$ & & $460-920$ & & $460-920$ & & $460-920$ \\
\hline $\mathrm{K}(\mathrm{mg})$ & & 2800 & & 2800 & & 3200 \\
\hline
\end{tabular}

EAR, Estimated Average Requirement; Al, Adequate Intake.

tThis is for dietary intake. For pregnant women, it does not include the additional supplemental folic acid required to prevent neural tube defects.

fDuring second and third trimester only. 


\section{Discussion}

This is the first comprehensive report of dietary intake in a nationally representative sample of Australian women, by pregnancy status. We have investigated the diet quality of a large cohort of young Australian women aged 25 to 30 years participating in the ALSWH and have compared nutrient intakes with the nationally recommended values. The findings indicate that there is room for improvement in dietary quality within this population.

Between pregnancy categories there were no differences in mean diet quality scores as summarised using the ARFS. The diet quality and variety of the young Australian cohort that we have studied appears to be suboptimal, as evident by the discrepancies between the recommended and reported intake levels, especially for folate, fibre and Fe. These key nutrients have also been found to be at suboptimal levels of intake in pregnant women in the UK and Norway, and in pregnant and non-pregnant controls in the USA ${ }^{(5-7)}$.

The ARFS was previously developed to evaluate the diet quality of mid-aged Australian women and it has performed well in analyses of nutritional and some morbidity-related indices ${ }^{(24,25)}$. While the absolute values of the ARFS are somewhat abstract, the diet quality score provides a useful means of ranking nutrient intakes and food variety at a population level. Analyses by component sub-scores highlight where improvements in specific food groups may be needed for young women and the food frequency data further delineate the 'at risk' nutrients.

No individual component accounted for a difference of one whole point or more on average between pregnancy categories and all components had potential for significant improvement in their scores. The grains and protein foods, especially nuts/beans/soya/eggs and fish, were the food groups most poorly scored across all pregnancy groups. To achieve a higher grain score, and thereby total ARFS, one would need to consume a variety of high-fibre and wholegrain bread and cereals, and include basic ingredients like pasta, rice and noodles, on average more than once per week (no quantity specified). It is likely that the poor reported intake of grain-based products is directly related to the low folate status of the young cohort, given that folate fortification of breads and cereals is common within the Australian food supply.

Nutritional requirements are generally higher during pregnancy and lactation with a few exceptions. For example, Fe requirements are lowest during lactation. The intakes of the selected nutrients included in the present analyses were consistently higher in women who were pregnant or had given birth in the previous 12 months, compared with those trying to conceive or otherwise not pregnant. However some important nutrients consistently fell short of national targets. Most notable were the low intakes of dietary folate irrespective of pregnancy status. The EAR for folate is from dietary intake and does not include the additional folic acid required pre-pregnancy and during the first trimester to prevent neural tube defects ${ }^{(31)}$. This dietary deficit is a major cause for concern as many pregnancies are unplanned and supplementation may not occur prior to the closure of the neural tube, if at all. An analysis of recent population-based data from Victoria (The Victorian Survey of Recent Mothers 2000) and New South Wales (The NSW Child Health Survey 2001), Australia, found that only 36\% and $46 \%$ of women in these respective states used periconceptional folic acid supplements ${ }^{(34)}$. This emphasises the importance of dietary folate in women of childbearing age and lends support to the perceived need for mandatory folic acid fortification.

The sociodemographic data for this cohort have been compared with Australian census data and it is deemed to be a reasonably representative national sample ${ }^{(21)}$. We have subdivided this cohort according to whether the women reported being currently pregnant, a birth in the previous 12 months, actively trying to conceive or 'other'. While childbearing years span beyond the 25 to 30 years aged cohort included in the present study, there is evidence to suggest this as an age-appropriate target group. In 2004 the median age of Australian women giving birth was $30 \cdot 0$ years ${ }^{(35)}$. The average age of first-time mothers was $28 \cdot 0$ years and this group accounted for $42 \cdot 2 \%$ of all women who gave birth ${ }^{(35)}$.

In light of the original ARFS analyses that were undertaken $^{(25)}$, it would be reasonable to hypothesise that diet quality improves with age, at least in women between their late twenties and early fifties. However, the association between diet quality, pregnancy status and age would require further investigation.

Clearly dietary requirements and intake change in response to pregnancy ${ }^{(36)}$. The present study suggests that diet variety and representation of good-quality foods do not necessarily improve in the lead up to or during pregnancy. Results for the 40108 study participants enrolled in the Norwegian MoBa Study also support this, with evidence that pregnant women do not generally change the types of foods they consume but rather the relative amounts ${ }^{(8)}$. Exceptions to this may include soft drinks, coffee and alcohol; however, these beverage items have not been included in our analyses and are therefore unlikely to influence our results.

\section{Limitations}

The DQES asks participants to report their usual intake for the previous 12 months. A significant limitation of the present study is that women did not specify how far along in their pregnancy they were at the time of completing the survey. It is well established that foods consumed near the time of completing an FFQ prime the memory such that the responses emphasise recently consumed 
foods ${ }^{(37)}$. However, some potential differences between categories may have been reduced or lost as a result of the extended time interval covered by this FFQ.

Measurement error is inherent in all methods of dietary data collection. For FFQ, this is introduced because of difficulties in estimating usual frequency and relative quantities of intake over time. The ARFS reduces this measurement error by dichotomising the frequency data and by including only a few points which relate to easily quantifiable amounts (for example, two fruit servings/d). The original validation study of the DQES which compared the FFQ with $7 \mathrm{~d}$ weighed food records reports less than $10 \%$ variation in mean nutrient intakes for most nutrients (carbohydrate-related and vitamin A-related nutrients varied more) ${ }^{(23)}$.

The DQES is a computer scannable FFQ that is purchased and processed by the Cancer Council of Victoria, Australia. In the processing of the FFQ for the young cohort, any questions that were either missed or not answered by participants were coded as never having consumed that food or beverage item. This was a change in the analysis protocol between the processing of the mid-aged and young surveys. In the dietary analyses for the mid-aged cohort, missing data were coded as such. By replicating the same coding series for the mid-aged data set, we were able to assess whether this change may have affected the ARFS obtained for the young cohort. A comparison of mean ARFS depending on coding protocol showed no significant difference.

It is important to note that these analyses include only food and beverage data and do not report on any vitamin and/or mineral supplementation, or enteral/parenteral sources of nutrients, as this information was unavailable. These sources may increase mean nutrient intakes and may also change the nutrient profiles across the different groups, given that vitamin and mineral supplementation often commences at or around the time of a pregnancy ${ }^{(38)}$.

\section{Conclusion}

The present study represents the largest study in Australia to date and one of the largest international studies to have investigated diet quality in young women and to have described differences by pregnancy subgroup. Clearly, the diets of many young Australian women do not meet the current national recommendations outlined in the dietary guidelines, core foods and nutrient reference values and this result is likely to be mirrored in other Western countries. In these analyses, this is a consistent finding among all young women, irrespective of being pregnant, not pregnant, having recently had a baby or trying to conceive. This is cause for concern given the prominence of current hypotheses relating maternal nutrition pre-conception and during pregnancy to the long-term health of their children.

\section{Acknowledgements}

The Australian Longitudinal Study on Women's Health, which was conceived and developed by groups of interdisciplinary researchers at the Universities of Newcastle and Queensland, is funded by the Australian Government Department of Health and Ageing. We thank all participants for their valuable contribution to this project. C.C. designed the study and directed its implementation, including quality assurance and control. A.Y. helped design the study and directed the statistical analyses. R.S. provided ongoing input into the implementation, quality assurance and control aspects of the projects. A.H. helped design the study, worked on the statistical analyses and was responsible for the project's implementation, including the preparation of the manuscript. All authors have made a significant contribution to the research and the development of the manuscript. We have no conflicts of interest to declare.

\section{References}

1. Koblinsky MA (1995) Beyond maternal mortality - magnitude, interrelationship, and consequences of women's health, pregnancy-related complications and nutritional status on pregnancy outcomes. Int J Gynaecol Obstet $\mathbf{4 8}$, Suppl., S21-S32.

2. Armitage JA, Khan IY, Taylor PD, Nathanielsz PW \& Poston L (2004) Developmental programming of the metabolic syndrome by maternal nutritional imbalance: how strong is the evidence from experimental models in mammals? J Physiol 561, 355-377.

3. Kind KL, Moore VM \& Davies MJ (2006) Diet around conception and during pregnancy - effects on fetal and neonatal outcomes. Reprod Biomed Online 12, 532-541.

4. Kuzawa CW (2005) Fetal origins of developmental plasticity: are fetal cues reliable predictors of future nutritional environments? Am J Hum Biol 17, 5-21.

5. Rogers I \& Emmett P (1998) Diet during pregnancy in a population of pregnant women in South West England. ALSPAC Study Team. Avon Longitudinal Study of Pregnancy and Childhood. Eur J Clin Nutr 52, 246-250.

6. Mouratidou T, Ford F, Prountzou F \& Fraser R (2006) Dietary assessment of a population of pregnant women in Sheffield, UK. Br J Nutr 96, 929-935.

7. Pick ME, Edwards M, Moreau D \& Ryan EA (2005) Assessment of diet quality in pregnant women using the Healthy Eating Index. J Am Diet Assoc 105, 240-246.

8. Meltzer HM, Brantsaeter AL, Ydersbond TA, Alexander J \& Haugen M (2008) Methodological challenges when monitoring the diet of pregnant women in a large study: experiences from the Norwegian Mother and Child Cohort Study (MoBa). Matern Child Nutr 4, 14-27.

9. Moore VM, Davies MJ, Willson KJ, Worsley A \& Robinson JS (2004) Dietary composition of pregnant women is related to size of the baby at birth. J Nutr 134, 1820-1826.

10. Zhou SJ, Schilling MJ \& Makrides M (2005) Evaluation of an iron specific checklist for the assessment of dietary iron intake in pregnant and postpartum women. Nutrition 21, 908-913.

11. Rumbold AR, Maats FH \& Crowther CA (2005) Dietary intake of vitamin $\mathrm{C}$ and vitamin $\mathrm{E}$ and the development of hypertensive disorders of pregnancy. Eur J Obstet Gynecol Reprod Biol 119, 67-71. 
12. Department of Health and Family Services (1998) National Nutrition Survey Users' Guide, 1995. Canberra: Australian Bureau of Statistics.

13. Australian Bureau of Statistics (2000) Special article: Food and nutrient consumption during pregnancy. In Births, Australia, 1999, pp. 16-19. Canberra: Australian Bureau of Statistics.

14. Nube M, Kok FJ, Vandenbroucke JP, van der Heide-Wessel C \& van der Heide RM (1987) Scoring of prudent dietary habits and its relation to 25-year survival. J Am Diet Assoc 87, 171-175.

15. Farchi G, Mariotti S, Menotti A, Seccareccia F, Torsello S \& Fidanza F (1989) Diet and 20-y mortality in two rural population groups of middle-aged men in Italy. Am J Clin Nutr 50, 1095-1103.

16. Haines PS, Siega-Riz AM \& Popkin BM (1999) The Diet Quality Index revised: a measurement instrument for populations. J Am Diet Assoc 99, 697-704.

17. Carmichael SL, Shaw GM, Selvin S \& Schaffer DM (2003) Diet quality and risk of neural tube defects. Med Hypotheses 60, 351-355.

18. Kant AK, Schatzkin A, Graubard BI \& Schairer C (2000) A prospective study of diet quality and mortality in women. JAMA 283, 2109-2115.

19. Philipps C \& Johnson NE (1977) The impact of quality of diet and other factors on birth weight of infants. Am J Clin Nutr 30, 215-225.

20. Brown WJ, Bryson L, Byles JE, Dobson AJ, Manderson L, Schofield M \& Williams G (1996) Women's Health Australia: establishment of the Australian Longitudinal Study on Women's Health. $J$ Womens Health 5, 467-472.

21. Brown WJ, Bryson L, Byles JE, Dobson AJ, Lee C, Mishra G \& Schofield M (1998) Women's Health Australia: recruitment for a national longitudinal cohort study. Women Health 28, 23-40.

22. Lee C, Dobson AJ, Brown WJ, Bryson L, Byles J, WarnerSmith P \& Young AF (2005) Cohort profile: the Australian Longitudinal Study on Women's Health. Int J Epidemiol 34, 987-991.

23. Hodge A, Patterson AJ, Brown WJ, Ireland P \& Giles G (2000) The Anti Cancer Council of Victoria FFQ: relative validity of nutrient intakes compared with weighed food records in young to middle-aged women in a study of iron supplementation. Aust $N Z$ J Public Health 24, 576-583.

24. Collins C, Hodge A \& Young A (2005) Are you what you eat? Associations between diet quality and health utilisation in mid-aged women from the Australian Longitudinal Study of Women's Health. Presented at 23rd National DAA Conference, Perth, Australia, 26-28 May 2005.
25. Collins CE, Young AF \& Hodge A (2008) Diet quality is associated with higher nutrient intake and self rated health in mid aged women. J Am Coll Nutr 27, 146-157.

26. Young AF, Powers JR \& Bell SL (2006) Attrition in longitudinal studies: who do you lose? Aust $N$ Z J Public Health 304, 353-361.

27. Kant AK \& Thompson FE (1997) Measures of overall diet quality from a food frequency questionnaire: National Health Interview Survey, 1992. Nutr Res 17, 1443-1456.

28. National Health and Medical Research Council (2003) Dietary Guidelines for Australian Adults. Canberra: Australian Government Publishing Service.

29. Smith A, Kellett E \& Schmerlaib Y (1998) The Australian Guide to Healthy Eating. Canberra: Australian Government Publishing Service.

30. National Health and Medical Research Council (2001) Australian Alcohol Guidelines. Health Risks and Benefits. Canberra: Australian Government Publishing Service.

31. National Health and Medical Research Council (2006) Nutrient Reference Values for Australia and New Zealand. Canberra: Commonwealth of Australia.

32. Black AE (2000) Critical evaluation of energy intake using the Goldberg cut-off for energy intake:basal metabolic rate. A practical guide to its calculation, use and limitations. Int J Obes Relat Metab Disord 24, 1119-1130.

33. Andresen EM, Malmgren JA, Carter WB \& Patrick DL (1994) Screening for depression in well older adults: evaluation of a short form of the CES-D (Center for Epidemiologic Studies Depression Scale). Am J Prev Med 10, 77-84.

34. Watson LF, Brown SJ \& Davey MA (2006) Use of periconceptional folic acid supplements in Victoria and New South Wales, Australia. Aust N Z J Public Health 30, 42-49.

35. Laws P, Grayson N \& Sullivan E (2006) Australia's Mothers and Babies 2004. AIHW Catalogue no. PER 34. Sydney: AIHW National Perinatal Statistics Unit.

36. Rifas-Shiman SL, Rich-Edwards JW, Willett WC, Kleinman KP, Oken E \& Gillman MW (2006) Changes in dietary intake from the first to the second trimester of pregnancy. Paediatr Perinat Epidemiol 20, 35-42.

37. Fowke JH, Schlundt D, Gong Y, Jin F, Shu XO, Wen W, Liu DK, Gao YT \& Zheng W (2004) Impact of season of food frequency questionnaire administration on dietary reporting. Ann Epidemiol 14, 778-785.

38. Forster DA, Wills G, Denning A \& Bolger M (2007) The use of folic acid and other vitamins before and during pregnancy in a group of women in Melbourne, Australia. Midwifery (Epublication ahead of print version). 